\title{
ERRATUM
}

E. A. T. Evers - D. E. Tillie - F. M. van der Veen •

C. K. Lieben · J. Jolles • N. E. P. Deutz • J. A. J. Schmitt

\section{Effects of a novel method of acute tryptophan depletion on plasma tryptophan and cognitive performance in healthy volunteers}

Published online: 2 October 2004

(C) Springer-Verlag 2004

\section{Psychopharmacology (2004) DOI 10.1007/s00213- 004-1933-4}

Unfortunately the acknowledgment was missing. It is given here. The authors apologize for this error.

Acknowledgment E. A. T. Evers, F. M. van der Veen and J. Jolles are funded by the ZonMW grant 912-02-050.

The online version of the original article can be found at http://dx. doi.org/10.1007/s00213-004-1933-4

E. A. T. Evers $(\bowtie) \cdot$ D. E. Tillie $\cdot$ F. M. van der Veen

C. K. Lieben · J. Jolles $\cdot$ J. A. J. Schmitt

Department of Psychiatry and Neuropsychology (DRT10),

Brain and Behavior Institute, Maastricht University,

P.O. Box 616 Maastricht, 6200, The Netherlands

e-mail: 1.evers@np.unimaas.nl

Tel.: +31-43-3884086

Fax: $+31-43-3884092$

N. E. P. Deutz

Department of Surgery, Maastricht University,

Maastricht, 6200, The Netherlands 